\title{
Article
}

\section{Diversity of Solvent Dependent Energy Transfer Pathways in Heme Proteins}

Yong Zhang, and John E. Straub

J. Phys. Chem. B, 2009, 113 (3), 825-830 • DOI: 10.1021/jp807499y • Publication Date (Web): 30 December 2008

Downloaded from http://pubs.acs.org on January 16, 2009

\section{More About This Article}

Additional resources and features associated with this article are available within the HTML version:

- $\quad$ Supporting Information

- $\quad$ Access to high resolution figures

- $\quad$ Links to articles and content related to this article

- Copyright permission to reproduce figures and/or text from this article

\section{View the Full Text HTML}




\title{
Diversity of Solvent Dependent Energy Transfer Pathways in Heme Proteins
}

\author{
Yong Zhang and John E. Straub* \\ Department of Chemistry, Boston University, Boston, Massachusetts, 02215
}

Received: August 21, 2008; Revised Manuscript Received: November 7, 2008

\begin{abstract}
The time scales and pathways of heme cooling in both reduced cytochrome $\mathrm{c}$ and oxidized cytochrome $\mathrm{c}$ following heme photoexcitation were studied using molecular dynamics simulation. Five different solvent models, including normal water, heavy water, normal glycerol, deuterated glycerol, and a nonpolar solvent, were used in the simulation. Single exponential decay of the excess kinetic energy of the heme following photoexcitation was observed in all systems studied. The simulated time scale for heme cooling in normal water agrees with recent experimental results. In contrast to heme cooling in myoglobin, no solvent dependence was observed for the time scale for heme cooling in cytochrome c. The diversity of solvent dependence results from the different local heme environments in the two proteins. In myoglobin, it has been established that the dominant mechanism for heme cooling is direct energy transfer from the heme to the solvent. In cytochrome c, direct interaction between heme and protein residues forms the dominant energy transfer pathway. This distinction is dictated by protein topology and linked to function.
\end{abstract}

\section{Introduction}

Vibrational energy relaxation (VER) in heme proteins following photoexcitation has been widely studied. Understanding the time scales and mechanisms of VER in these systems is an essential component of an understanding of how molecular dynamics, intramolecular interactions, solvent effects, and conformational change is exploited in molecular signaling pathways. ${ }^{1-6}$

Myoglobin (Mb) is the most studied and best understood heme protein with respect to heme relaxation, energy transfer, conformational change, and the possible connection to allostery, signaling, and function. ${ }^{7-19}$ In their time-resolved Raman spectral study, Martin and co-workers found that the excess energy deposited in the heme is transferred to protein modes in roughly 5 ps. Within 15 ps, the excess energy of the heme was fully dissipated. ${ }^{20} \mathrm{Lim}$ and co-workers identified a heme cooling time constant of $6.2 \pm 0.5$ ps following photoexcitation in myoglobin. ${ }^{21}$ On the basis of Raman scattering experiments, $\mathrm{Li}$, Sage, and Champion observed a decay with a time constant of 4 ps. $^{22}$

Using molecular dynamics simulation, Sagnella and Straub found that the heme kinetic energy decayed as a single exponential with a time constant of 5.9 ps following $\mathrm{CO}$ dissociation in both native myoglobin and H93G mutated myoglobin..$^{23,24}$ For modified myoglobin, in which the two isopropionate side chains are replaced by aliphatic hydrogens, the relaxation time constant increased to $8.8 \mathrm{ps}$. The strong interaction between the isopropionate side chains and solvent was conjectured to be the dominant pathway for heme cooling. ${ }^{24}$ This conjecture was supported by subsequent experimental studies on the $\mathrm{H} 93 \mathrm{G}$ mutant and similar modified heme variants of myoglobin. ${ }^{25-27}$

Another widely studied heme protein is cytochrome c (Cyt c). ${ }^{4,28-33}$ The heme in Cyt c can assume reduced (Fe(II)) and oxidized (Fe(III)) forms, related to its function as an electron carrier. Most studies so far have focused on reduced heme Cyt c. Champion and co-workers studied the electronic and vibra-

\footnotetext{
*E-mail:straub@bu.edu.
}

tional relaxation dynamics of heme in Fe(II) Cyt c using resonance Raman saturation spectroscopy. ${ }^{22}$ It was found that the electronic relaxation time constant is $6.4 \pm 2.0 \mathrm{ps}$, the heme cooling follows a single exponential decay with a time constant of roughly $4 \mathrm{ps}$. Photodissociation of heme axial ligand in $\mathrm{Fe}(\mathrm{II})$ Cyt c was studied by Traylor and co-workers. ${ }^{34}$ The Fe-His 18 bond was declared to be broken after $314 \mathrm{~nm}$ photoexcitation and the subsequent geminate rebinding was observed to have a time constant of $6.7 \mathrm{ps}$. Axial ligand photodissociation in $\mathrm{Fe}(\mathrm{II})$ Cyt $\mathrm{c}$ was also observed in a later study by Champion and coworkers. ${ }^{35}$ The authors found that the distal ligand of the heme, Met80, was photodissociated. A multistep heme cooling process with time constants of $0.1,0.8$, and 2.8 ps was reported. Recent work by Kruglik and co-workers using $550 \mathrm{~nm}$ photon excitation confirmed the photodissociation of Met80, as opposed to His18, in reduced Cyt c. ${ }^{36}$ The oxidized Cyt $\mathrm{c}$ was also studied with no evidence of ligand photodissociation. The heme cooling was found to be single exponential for both $\mathrm{Fe}$ (II) Cyt $\mathrm{c}$ and $\mathrm{Fe}(\mathrm{III})$ Cyt $\mathrm{c}$ with a time constant of roughly $7 \mathrm{ps}$.

Molecular dynamics simulation of $\mathrm{Fe}(\mathrm{II}) \mathrm{Cyt} \mathrm{c}$, ignoring photodissociation, led to the observation of a biphasic exponential decay process of heme cooling with relaxation time constants 1.5 and $10.1 \mathrm{ps} .{ }^{37}$ Energy flow from the heme to the protein was found to occur "through bond", via covalent linkages and hydrogen bonds to protein residues, and "through space", via nonbonded collision channels.

In a recent molecular dynamics simulation work, we studied the solvent dependence of heme cooling in $\mathrm{Mb}$ using a variety of solvents including water, heavy water, and glycerol. ${ }^{38} \mathrm{~A}$ dramatic solvent dependence was observed. The dependence can not be explained using the bulk transport properties of the solvents. It was found that heme cooling depends on the detailed microscopic interaction between the heme and solvent. Three intermolecular energy transfer mechanisms-energy transfer mediated by hydrogen bonds, direct vibration-vibration energy transfer via resonant interaction, and energy transfer via thermal collision-were discussed for each solvent solution studied. In this work, we extended the solvent dependence study to Cyt c, in which the heme moiety has a different local environment 

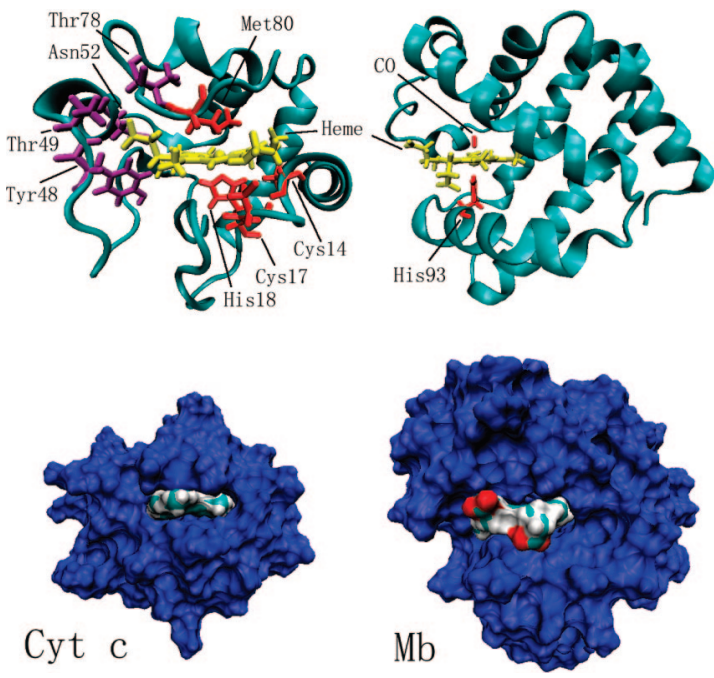

Figure 1. (top) Structure of cytochrome c (Cyt c) and carbonmonoxy myoglobin $(\mathrm{Mb})$ with heme (shown in yellow), residues covalently bonded to heme (red), and residues hydrogen bonded to heme (purple). (bottom) Depiction of the heme exposure to solvent in the two proteins with surface filled model. The protein residues were shown in blue and the heme was shown with color code (red for $\mathrm{O}$, cyan for $\mathrm{C}$, and white for $\mathrm{H}$ ). The heme in $\mathrm{Mb}$ is more exposed to solvent than the heme in Cyt c.

relative to that in $\mathrm{Mb}$ supporting a different protein function. Five solvent models, including normal water, heavy water, normal glycerol, deuterated glycerol, and a nonpolar solvent, were applied to both reduced Cyt $\mathrm{c}$ and oxidized Cyt $\mathrm{c}$. The photoexcited state of the heme was carefully prepared and the recently refined penta-coordinate parameters for the photodissociated heme were used. For the systems studied, the only direct interaction between heme and solvent was found to be weak thermal collision. No significant solvent dependence was observed for heme cooling in reduced Cyt $\mathrm{c}$ or oxidized Cyt $\mathrm{c}$. It is conjectured that the diverse solvent dependence observed reflects and supports the diversity of protein function.

\section{Computational Methods}

2.1. Molecular Dynamics Simulation. The computational protocol follows that developed by Zhang and Straub. ${ }^{38}$ The initial configuration of the horse heart Cyt c protein was taken from the Protein Data Bank X-ray crystal structure of the oxidized form (PDB ID 1HRC; see Figure 1). ${ }^{39}$ As the difference between the reduced and oxidized Cyt $\mathrm{c}$ structure is within the limit of resolution, we took the 1HRC structure as our initial structure for both the reduced and the oxidized form of Cyt c. Molecular dynamics simulations were carried out using the CHARMM program ${ }^{40}$ with the all-hydrogen parameter set of the CHARMM force field (version 22) ${ }^{41}$ The atomic point charges of the oxidized heme were taken from ab initio calculations $^{42}$ using the GAUSSIAN 92 program.

Five solvent models, normal water $\left(\mathrm{H}_{2} \mathrm{O}\right)$, heavy water $\left(\mathrm{D}_{2} \mathrm{O}\right)$, normal glycerol $\left(\mathrm{gly}-\mathrm{h}_{8}\right)$, deuterated glycerol $\left(\mathrm{gly}_{\mathrm{f}} \mathrm{d}_{8}\right)$, and a nonpolar solvent, were used. The CHARMM version of the modified TIP3P water model ${ }^{43}$ was used for both $\mathrm{H}_{2} \mathrm{O}$ and $\mathrm{D}_{2} \mathrm{O}$ simulation with the masses of hydrogen atoms appropriate for $\mathrm{D}_{2} \mathrm{O}$. Gly- $\mathrm{h}_{8}$ parameters consistent with the all atom CHARMM force field were used. ${ }^{44}$ The same parameters were used for gly$\mathrm{d}_{8}$ with an increase in mass for all $\mathrm{H}$ atoms. An extended atom model ${ }^{45}$ was used as the "nonpolar solvent", in which the atoms have no charge or dipole moment and so interact only through the van der Waals term in the interaction potential.
The molecular dynamics was simulated using the Verlet algorithm ${ }^{46}$ with periodic boundary conditions and a time step of $1.0 \mathrm{fs}$. The nonbonded potential was truncated using a group switching function extending from 9.5 to $11.5 \AA$. For simulations in nonpolar solvents, weak harmonic constraints (about $6 \mathrm{kcal} /$ $\left(\mathrm{mol} \cdot \AA^{2}\right)$ ) were added to all protein $\mathrm{C}_{\alpha}$ atoms to maintain the protein's native structure. The temperature of the simulation system was increased slowly to $300 \mathrm{~K}$. A molecular dynamics trajectory was run at constant pressure and constant temperature for $\mathrm{H}_{2} \mathrm{O}$ solution and gly- $\mathrm{h}_{8}$ solution, respectively, after which the volume of the box was found to fluctuate about a constant mean value. The water box was $71.07 \times 71.07 \times 54.55 \AA^{3}$, containing 9223 solvent molecules; the glycerol box was 66.46 $\times 66.46 \times 58.08 \AA^{3}$ containing 1830 solvent molecules. The final parameters of the $\mathrm{H}_{2} \mathrm{O}$ box were used for $\mathrm{D}_{2} \mathrm{O}$ and nonpolar solvent; those of the $g l y-h_{8}$ box were used for $g l y-d_{8}$ box. Chloride ions were included to make each system charge neutral.

For each system, $20 \mathrm{ps}$ of constant temperature molecular dynamics was run in which the temperature was checked every $0.2 \mathrm{ps}$ for the first $10 \mathrm{ps}$ and every $2.0 \mathrm{ps}$ for the other $10 \mathrm{ps}$. During the last $10 \mathrm{ps}$, the average temperature remained within the $5 \mathrm{~K}$ window, and there was no need to resample the atomic velocities. The system was then allowed to evolve for an additional 200 ps. Coordinates were saved every 20 ps for a total of 10 configurations. Each of these configurations was then run for 20 ps with the velocities resampled following the same protocol. Ten $50 \mathrm{ps}$ microcanonical trajectories were generated from the nonequilibrium (photoexcited) state.

2.2. Simulation of Photon Absorption by the Heme. To simulate the absorption of a photon, approximately $52 \mathrm{kcal} /$ mol of excess kinetic energy, equivalent to a $550 \mathrm{~nm}$ photon, was deposited in the heme of Fe(III) Cyt c. For Fe(II) Cyt c, a portion of the photon energy was used to break the $\mathrm{Fe}-\mathrm{S}$ bond between the heme and Met80, so that less energy was directly deposited in the heme. It has been reported that the binding enthalpy for $\mathrm{CO}$ to myoglobin is $\sim 22 \mathrm{kcal} / \mathrm{mol} .{ }^{47}$ It has also been suggested that the $\mathrm{Fe}-\mathrm{S}$ bond in cytochrome $\mathrm{c}$ is weaker than the $\mathrm{Fe}-\mathrm{CO}$ bond in carbonmonoxy myoglobin $(\mathrm{MbCO}){ }^{48-51}$ The exact binding enthalpy for the $\mathrm{Fe}-\mathrm{Met} 80$ bond in $\mathrm{Cyt} \mathrm{c}$ is not known to us.

Metalloporphyrin vibrational frequency shifts with temperature have been observed. ${ }^{52} \mathrm{We}$ assume that the excess energy deposited in the heme is predominantly converted to kinetic energy. On the basis of the experimentally measured frequency shift values of the $v_{4}$ mode of Fe(II) and Fe(III) Cyt c (15 and $17 \mathrm{~cm}^{-1}$, respectively $)^{36}$ and the temperature-frequency relation reported for a nickel porphyrin, ${ }^{52}$ we determined $\Delta H$ for the $\mathrm{Fe}-\mathrm{S}$ bond to be $14 \mathrm{kcal} / \mathrm{mol}$ which implies that $\sim 38 \mathrm{kcal} / \mathrm{mol}$ of excess energy was left in the heme after the photodissociation of Met80 upon the absorption of a $550 \mathrm{~nm}$ photon. Several other values of the excitation energy between 30 and $52 \mathrm{kcal} / \mathrm{mol}$ were examined and the energy relaxation rate was found to be similar. In this work, $38 \mathrm{kcal} / \mathrm{mol}$ of excess kinetic energy was deposited in the heme of $\mathrm{Fe}(\mathrm{II}) \mathrm{Cyt} \mathrm{c}$ after Met80 photodissociation and $52 \mathrm{kcal} / \mathrm{mol}$ was deposited in $\mathrm{Fe}(\mathrm{III})$ heme without ligand photodissociation.

It was found that the intramolecular vibrational energy relaxation within the heme was sufficiently rapid that the results were insensitive to the exact means of distributing the excess energy within the heme. ${ }^{23}$ In this work, the excess kinetic energy was distributed uniformly among all the heme atoms, leading to a temperature increase of about $180 \mathrm{~K}$ for $\mathrm{Fe}(\mathrm{II})$ heme and 

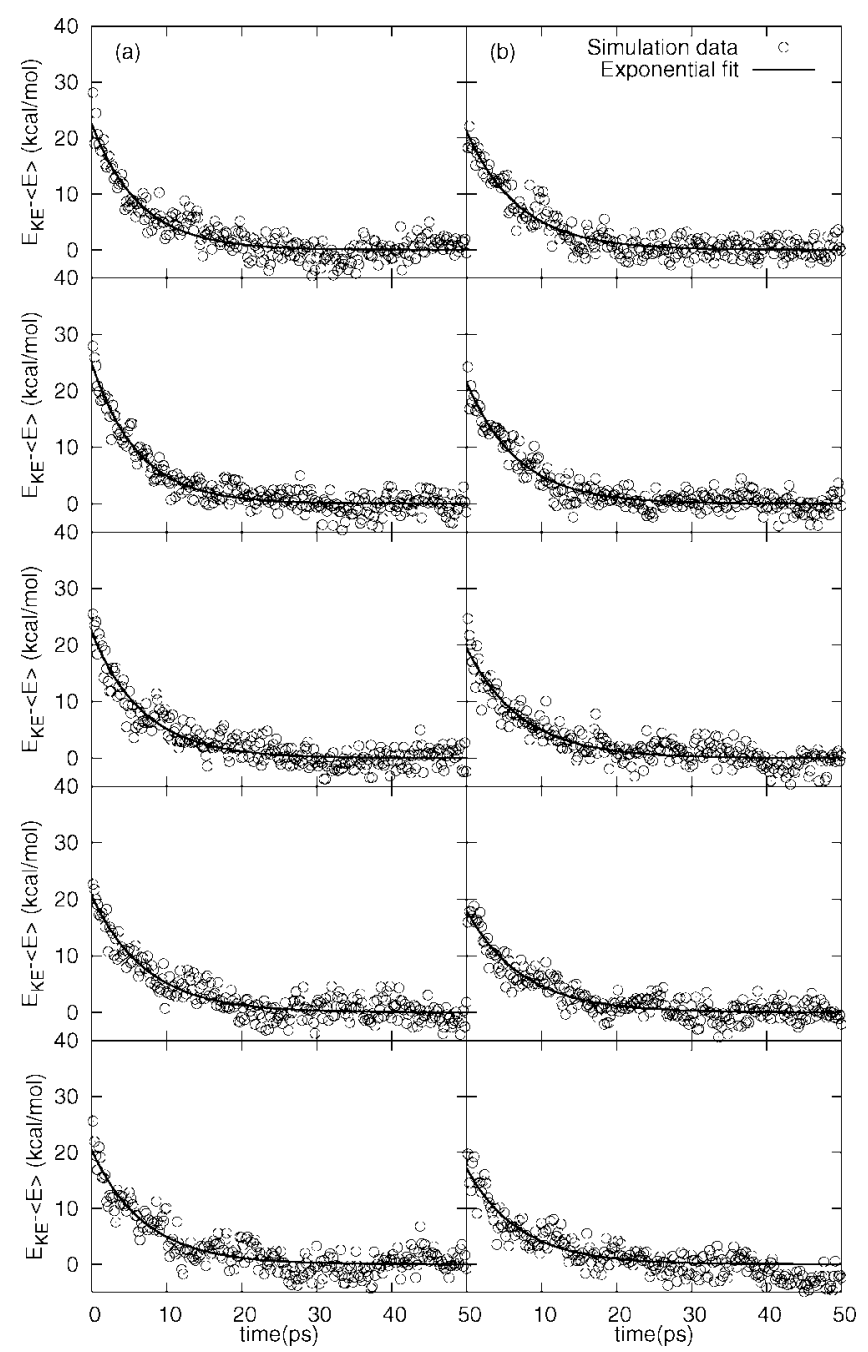

Figure 2. Exponential decay of excess heme kinetic energy following photoexcitation. The simulation data are represented by points around the best single-exponential fit. (a) Fe(II) heme following $38 \mathrm{kcal} / \mathrm{mol}$ excitation with photodissociation of Met80 considered. (b) Fe(III) heme following $52 \mathrm{kcal} / \mathrm{mol}$ excitation without ligand photodissociation. The solvents are, from top to bottom, normal water $\left(\mathrm{H}_{2} \mathrm{O}\right)$, heavy water $\left(\mathrm{D}_{2} \mathrm{O}\right)$, normal glycerol $\left(\right.$ gly- $\left.\mathrm{h}_{8}\right)$, deuterated glycerol (gly- $\left.\mathrm{d}_{8}\right)$, and a nonpolar atomic solvent model. The decay time constants are summarized in Table 1 .

$250 \mathrm{~K}$ for Fe(III) heme. Recently refined penta-coordinate heme parameters $^{53}$ were used to describe the Fe(II) heme following photolysis.

The rebinding of Met80 to heme has been reported from experiments. ${ }^{35,36}$ It has been shown that the axial ligand does not contribute in a significant way to the heme cooling, and there is no evidence from experiment that rebinding causes a significant energy change in the heme of Fe(II) Cyt c. ${ }^{36}$ As such, we did not simulate the Met80 rebinding explicitly and focused on the heme cooling due to the initial photoexcitation.

\section{Results and Analysis}

3.1. Diversity of Heme Cooling in Cyt $\mathrm{c}$ and Mb. Simulated nonequilibrium dynamics trajectories were used to determine the time scales of kinetic energy relaxation or heme cooling in cytochrome c. The average time dependence of the excess kinetic energy decay in the heme for each case is shown in Figure 2. The simulation data is well fitted by a single exponential decay function (see Table 1). This differs from the previously reported double exponential decay. ${ }^{37}$ In that work, a
TABLE 1: Excess Heme Kinetic Energy Relaxation Time Constants Following Photoexcitation Simulated at $300 \mathbf{K}^{a}$

\begin{tabular}{lcc}
\hline & \multicolumn{2}{c}{ time constant $(\mathrm{ps})$} \\
\cline { 2 - 3 } solvent & $\mathrm{Fe}(\mathrm{II}) \mathrm{Cyt} \mathrm{c}$ & $\mathrm{Fe}(\mathrm{III}) \mathrm{Cyt} \mathrm{c}$ \\
\hline $\mathrm{H}_{2} \mathrm{O}$ & $6.4 \pm 0.4$ & $7.0 \pm 0.4$ \\
$\mathrm{D}_{2} \mathrm{O}$ & $6.2 \pm 0.3$ & $6.8 \pm 0.3$ \\
gly- $_{8}$ & $6.8 \pm 0.4$ & $7.3 \pm 0.4$ \\
gly-d & $7.2 \pm 0.4$ & $7.4 \pm 0.4$ \\
nonpolar & $7.0 \pm 0.5$ & $7.0 \pm 0.7$
\end{tabular}

${ }^{a}$ For each solvent, $38 \mathrm{kcal} / \mathrm{mol}$ of excess kinetic energy was deposited in the heme of $\mathrm{Fe}(\mathrm{II}) \mathrm{Cyt} \mathrm{c}$ after Met80 photodissociation and $52 \mathrm{kcal} / \mathrm{mol}$ was deposited in Fe(III) Cyt $\mathrm{c}$ in the absence of ligand photodissociation. The simulation data were well-fitted by a single-exponential function in each case.

reduced Cyt $\mathrm{c}$ was studied without explicit consideration of the ligand dissociation. Our current work, which employs a more accurate model including ligand photodissociation, leads to results in better agreement with experiment.

In $\mathrm{H}_{2} \mathrm{O}$ solutions, $\mathrm{Fe}(\mathrm{II})$ heme and $\mathrm{Fe}(\mathrm{III})$ heme have relaxation time constants of $6.4 \pm 0.4$ and $7.0 \pm 0.4 \mathrm{ps,}$ respectively. These results agree well with the recent experimental measurements of 6.8 ps for $\mathrm{Fe}(\mathrm{II}) \mathrm{Cyt} \mathrm{c}$ and 7.3 ps for $\mathrm{Fe}(\mathrm{III}) \mathrm{Cyt} \mathrm{c}^{36}$ indicating that the classical dynamics employed provides a reasonable description of the relaxation process.

In contrast to our results for $\mathrm{Mb},{ }^{38}$ the deuteration of water hydrogens did not change the heme cooling rate for either $\mathrm{Fe}(\mathrm{II})$ Cyt c or Fe(III) Cyt c. The same result was observed for gly-h 8 deuteration to gly- $_{8}$, in which $\mathrm{Fe}$ (II) heme and $\mathrm{Fe}$ (III) heme have similar heme cooling rates.

For Fe(II) Cyt $\mathrm{c}$ in nonpolar solution, the heme cooling rate is similar to that in glycerol solutions, and it is slightly slower than in water solution. For Fe(III) heme, the relaxation rate of the heme in all solutions was observed to be similar to that in water. For both water solutions and glycerol solutions, the Fe(II) heme relaxed marginally faster than the Fe(III) heme. Within the statistical uncertainty, all systems studied have the same energy relaxation time constants.

In our previous study on myoglobin, ${ }^{38}$ the deuteration of solvent hydrogens changed the heme cooling rate dramatically for water solutions. This effect was ascribed to changes in the density of vibrational states that influence vibration-vibration resonance properties between the heme and solvent. This isotope dependence was also found for $\mathrm{Mb}$ in glycerol solutions. In addition, $\mathrm{Mb}$ heme cooling rates changed when the solvent was changed from water to glycerol to a nonpolar solvent model. The diversity of heme cooling due to a change in solvent between myoglobin and cytochrome $\mathrm{c}$ results from the different local heme environment in the two proteins.

In myoglobin (see Figure 1), the heme is buried in the protein matrix with about 90 van der Waals interactions with the heme pocket residues and one covalent bond between heme iron atom and protein His 93 imidazole. The Fe-His93 bond is orthogonal to the heme plane, and it was found that its contribution to heme cooling is little. ${ }^{23-25}$ On the other hand, the two charged isopropionate side chains of the heme are accessible to solvent. They form strong direct interactions with the solvent, making energy transfer through hydrogen bonds and vibration-vibration interactions possible. The close contact between heme side chains and solvent also enhances energy transfer through thermal collision. As a result, the two isopropionate side chains played as the dominant energy transfer pathway in myoglobin.

In cytochrome $\mathrm{c}$, however, all three energy transfer pathways are missing or less effective. The two isopropionate side chains 


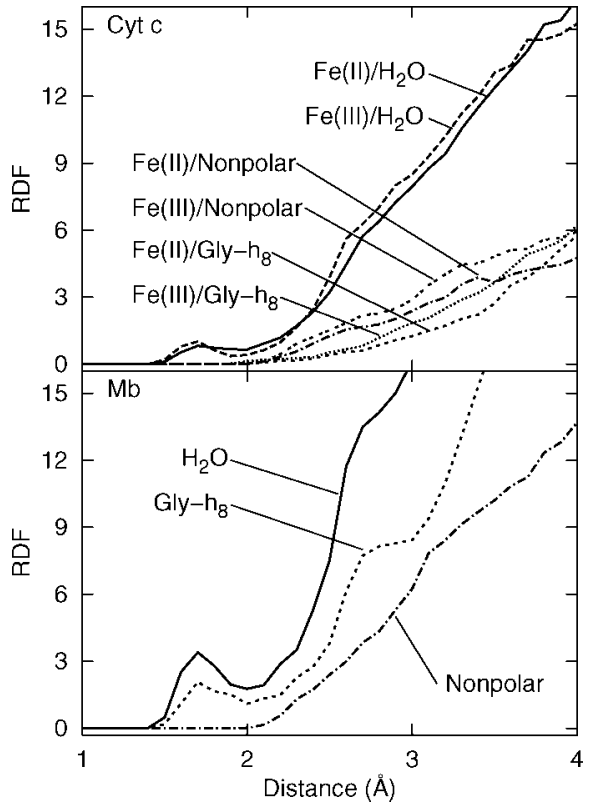

Figure 3. Radial distribution functions (RDFs) showing the structure of solvent atoms around the heme in cytochrome c (upper) and myoglobin (lower). The results were averaged over all heme atoms.

of heme in Cyt $\mathrm{c}$ are embedded in the protein and form hydrogen bonds with residues Tyr48, Thr49, Asn52, and Thr79 (see Figure 1). Energy transfer through hydrogen bonds to solvent was not possible as no hydrogen bonds with solvent were formed. The lack of deuteration dependence in the heme cooling rate suggests the absence of vibration-vibration energy transfer mechanism between heme and solvent in the Cyt c systems. ${ }^{54}$ This is consistent with the recent observation that the librational modes, defined as hydrogen bond hindered bending motion, play a key role in the vibration-vibration energy transfer mechanism. ${ }^{55}$ The only direct energy transfer pathway between Cyt c heme and solvent is thermal collision. The radial probability function describing the distribution of heme-solvent atomic distances is shown in Figure 3 for $\mathrm{Mb}$ and Cyt $\mathrm{c}$ in varying solvents. The heme exposure to solvent is depicted in Figure 1. The thermal collision mechanism is less effective in Cyt $\mathrm{c}$ due to the poor contact when compared to $\mathrm{Mb}$.

The poor contact between heme and solvent molecules makes direct energy relaxation to solvent almost impossible in Cyt c. On the other hand, in addition to the hydrogen bonds to the isopropionate side chains, the heme is covalently bonded to four protein residues, Cys14, Cys17, His18, and Met80, as shown in Figure 1. These connections make the direct interactions between heme and protein residues the dominant energy transfer pathway in Cyt c. While we have demonstrated that the mechanism for heme cooling is distinctly different in $\mathrm{Mb}$ and Cyt c, we are unable to provide a more detailed quantitative analysis of the separate contributions of the many coupled channels to the overall heme cooling rates.

Why is the heme cooling faster in water solutions than in glycerol and in nonpolar solutions? We speculate that the more effective energy transfer through thermal collisions in water solutions results from the closer contact between the heme side chains and water hydrogen atoms, shown as the small peak around $\sim 1.7 \AA$ in Figure 3 .

3.2. Energy Redistribution Following Heme Photoexcitation in Cyt c. We would like to understand how Met80 photodissociation affects energy transfer in the Cyt c. The photodissociation of Met80 in Fe(II) Cyt $\mathrm{c}$ following the
TABLE 2: Excess Heme Kinetic Energy Relaxation Time Constants Following Photoexcitation Simulated at $10 \mathrm{~K}^{a}$

\begin{tabular}{lcc}
\hline & \multicolumn{2}{c}{ time constant (ps) } \\
\cline { 2 - 3 } solvent & $\mathrm{Fe}(\mathrm{II}) \mathrm{Cyt} \mathrm{c}$ & $\mathrm{Fe}(\mathrm{III}) \mathrm{Cyt} \mathrm{c}$ \\
\hline $\mathrm{H}_{2} \mathrm{O}$ & $12.1 \pm 0.4$ & $14.4 \pm 0.4$ \\
gly- $\mathrm{h}_{8}$ & $14.7 \pm 0.5$ & $16.2 \pm 0.6$
\end{tabular}

${ }^{a}$ See notes in Table 1.

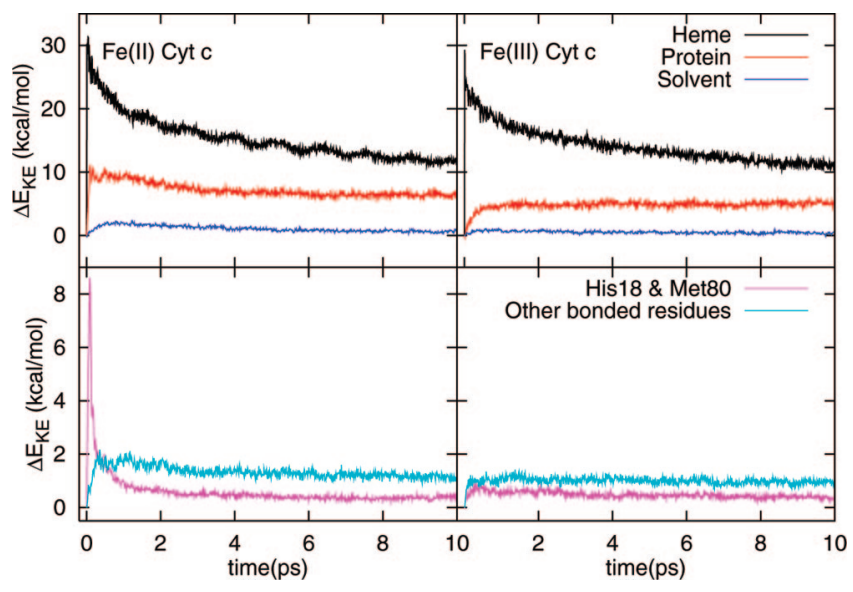

Figure 4. Excess kinetic energy redistribution in $\mathrm{Fe}(\mathrm{II})$ Cyt $\mathrm{c}_{2} \mathrm{O}$ solution (left) and $\mathrm{Fe}$ (III) $\mathrm{Cyt} \mathrm{c}_{2} \mathrm{O}$ solution (right) for the first $10 \mathrm{ps}$ following heme photoexcitation at $10 \mathrm{~K}$. "Other bonded residues" refers to protein residues bonded to the heme except His18 and Met80, including Cys14 and Cys17, which are covalently bonded to heme, and Tyr48, Thr49, Asn52, and Thr78, which are hydrogen bonded to the heme. The results were averaged over ten trajectories. The excess kinetic energy evolution in glycerol solutions shows similar profiles.

absorption of a photon of energy $52 \mathrm{kcal} / \mathrm{mol}$ results in a significant reduction in energy directly deposited in the heme relative to $\mathrm{Fe}$ (III) Cyt c. The Met80 dissociation causes heme doming motion that subsequently displaces the linked ligand His 18 to the proximal side and the Met80 side chain away from the heme on the distal side. The kinetic energy redistribution observed following heme photoexcitation was studied for $\mathrm{H}_{2} \mathrm{O}$ solutions and gly- $\mathrm{h}_{8}$ solutions. Due to large thermal fluctuations, it is difficult to follow the energy transfer at room temperature. We quenched the ten configurations prepared at $300 \mathrm{~K}$ to 10 $\mathrm{K}$. As has been shown in past studies, ${ }^{38,56}$ this approach provides qualitative insight in the heme cooling process occurring at high temperature.

The quenched configurations were re-equilibrated at $10 \mathrm{~K}$, and heme excitation and cooling was simulated. Velocities were saved every 10 steps. The heme cooling process is slower at this temperature but trends in the solvent dependence of the energy transfer are preserved (see Table 2). The kinetic energy of the heme, protein residues, and solvent molecules as a function of time is shown in Figure 4 for Cyt $\mathrm{c}_{2} \mathrm{O}$ solutions. To isolate the small energy change in the solvent over the large background energy from thousands of solvent molecules, we calculated the kinetic energy of those solvent molecules whose heavy atoms (O or $\mathrm{C}$ ) are within $8 \AA$ distance of any heme atoms. The assumption is that the energy transfer from protein residues to solvent is slow, as was previously observed. ${ }^{38}$

Following photoexcitation, the only source of excess energy for $\mathrm{Fe}$ (III) heme is the excitation photon. For Fe(II) heme, the kinetic energy increase stems from the excess energy due to photoexcitation and the heme doming motion following photolysis. The kinetic energy from heme doming balances the photon energy lost when breaking the Fe-Met80 bond. As 
shown in Figure 4, the increase in the kinetic energy of the heme was similar in both $\mathrm{Fe}(\mathrm{II}) \mathrm{Cyt} \mathrm{c}$ and $\mathrm{Fe}(\mathrm{III}) \mathrm{Cyt} \mathrm{c}$. Fe(II) heme and $\mathrm{Fe}(\mathrm{III})$ heme followed a similar cooling process: starting with $\sim 30 \mathrm{kcal} / \mathrm{mol}$ of excess kinetic energy, about 18 $\mathrm{kcal} / \mathrm{mol}$ was dissipated in $10 \mathrm{ps}$ and $12 \mathrm{kcal} / \mathrm{mol}$ remained in the heme.

The distribution of energy over protein residues is different in $\mathrm{Fe}$ (II) and $\mathrm{Fe}$ (III) Cyt c. After dissociation of Met80 in $\mathrm{Fe}$ (II) Cyt c, His 18 was displaced by the heme doming motion, and the energy increased by $10 \mathrm{kcal} / \mathrm{mol}$ dominating the energy increase in the protein. Subsequently, the kinetic energy in His18 and Met80 decreased quickly due to energy transfer to neighboring residues and conversion to potential energy. This process was accompanied by energy accumulation in residues with covalent bonds and hydrogen bonds to the heme, and residues with available through space energy transfer channels. After $10 \mathrm{ps}, 7 \mathrm{kcal} / \mathrm{mol}$ of excess energy remained in the protein. In $\mathrm{Fe}$ (III) Cyt c, the sudden energy jump was missing. The kinetic energy slowly increased to $6 \mathrm{kcal} / \mathrm{mol}$ in $1 \mathrm{ps}$ via through bond and through space channels and was observed to remain there for the remainder of the trajectory.

Following photoexcitation of the heme, the energy increase in the solvent of the Fe(III) Cyt c solution reached its maximum of $\sim 1 \mathrm{kcal} / \mathrm{mol}$ within $1 \mathrm{ps}$. The energy increase in Fe(II) Cyt c solvent was larger by $0.5 \mathrm{kcal} / \mathrm{mol}$ than in $\mathrm{Fe}(\mathrm{III})$ Cyt c solvent as a result of the significant protein atomic displacements triggered by the Met80 dissociation and heme doming. Few water molecules within $8 \AA$ distance of the heme have direct contact with His18, Met80, or nearby residues. It is likely that the doming motion excites solvent beyond $8 \AA$ within $10 \mathrm{ps,}$ delivering additional excess energy to water molecules. ${ }^{57,58}$

The kinetic energy redistribution is roughly the same in gly$\mathrm{h}_{8}$ solutions (not shown here) except that the solvent molecules have less energy due to poorer contact with heme (see Figure 3).

This analysis supports our conjecture that, due to the local environment of heme in Cyt c, the energy transfer between heme and solvent is ineffective. Direct interaction between heme and protein residues play a dominant role in the energy transfer pathway, resulting in the contrast between mechanisms for heme cooling in cytochrome $\mathrm{c}$ and myoglobin. Although there is a difference in energy redistribution in the system a short time after photoexcitation, the heme energy relaxation has a similar mechanism in all solvents studied. The change of solvent has no influence on the heme cooling rate for either Fe(II) Cyt $\mathrm{c}$ or $\mathrm{Fe}(\mathrm{III})$ Cyt c.

3.3. Distinct Heme-Solvent Interaction Dictated by Protein Function. It is clear from the above discussion that the diversity of solvent dependent energy transfer in Cyt $\mathrm{c}$ and $\mathrm{Mb}$ is due to the distinct heme-solvent interaction. The heme has been designed with different local environments in the two proteins to support varying protein function.

Myoglobin is generally found in muscle cells to store oxygen. The reversible binding and release of $\mathrm{O}_{2}$ ligand to the heme $\mathrm{Fe}$ atom dictates the somewhat open conformation of the Mb heme to solvent. It has been suggested that the hydrogen bonding status of the heme isopropionate side chains plays an important role in controlling the diatomic ligand escaping process from the heme pocket. ${ }^{59}$

Whereas cytochrome $\mathrm{c}$ does not bond $\mathrm{O}_{2}$ or other small ligand, it acts as an essential component of the electron transfer chain between the two large enzymes, cytochrome reductase and cytochrome oxidase. For example, the electron transfer process in cytochrome $\mathrm{c}$ and cytochrome $\mathrm{c}$ peroxidase $(\mathrm{CcP})$ complex has been widely studied. ${ }^{60-66}$ In this complex, one electron transfers from the $\mathrm{Cyt} \mathrm{c}$ heme to the $\mathrm{CcP}$ heme. It was found in the yeast $\mathrm{Cyt} \mathrm{c} / \mathrm{CcP}$ crystal structure that two hydrophobic resides from CcP, Ala193 and Ala194, have close contact with the methyl group of the Cyt $\mathrm{c}$ heme side chain. ${ }^{61}$ This methyl group, the docking site of Cyt c, locates on pyrrole ring $\mathrm{C}$ of the heme and is exposed to the solvent. Without significant overlap with the VER pathway, it was suggested that the electron is transferred through this hydrophobic interaction, following the pathway consisting of the Gly192 and Trp191 residues of $\mathrm{CcP}$, to reach the $\mathrm{CcP}$ heme. The weak interaction between the heme side chains and solvent molecules in Cyt c, as discussed above, preserved the methyl group for the docking process essential for the protein function. This mechanism is similar to that identified by Friesner and co-workers as "hydrophobic enclosure". ${ }^{67}$

\section{Summary and Conclusions}

The time scales and pathways of heme cooling in reduced and oxidized cytochrome $\mathrm{c}$ following heme photoexcitation were studied using nonequilibrium molecular dynamics simulation. Five different solvent models, including normal water, heavy water, normal glycerol, deuterated glycerol, and a nonpolar solvent, were used in the molecular dynamics simulation. The single exponential decay of the excess kinetic energy of the heme following photoexcitation was observed in all systems studied. For both Fe(II) Cyt c, with photodissociation of Met80, and $\mathrm{Fe}$ (III) Cyt c, without ligand photodissociation, the simulated heme cooling rates in $\mathrm{H}_{2} \mathrm{O}$, with time constants of $6.4 \pm 0.4 \mathrm{ps}$ and $7.0 \pm 0.4 \mathrm{ps}$, respectively, agree well with recent experimental results of $6.8 \mathrm{ps}$ for reduced heme and $7.3 \mathrm{ps}$ for oxidized heme. ${ }^{36}$

In contrast to heme cooling in myoglobin, ${ }^{38}$ no solvent dependent heme cooling was observed for either Fe(II) Cyt c or Fe(III) Cyt c. The heme was observed to relax with essentially the same rate in all solutions studied. The diversity of solvent dependent energy transfer pathways in Cyt $\mathrm{c}$ and $\mathrm{Mb}$ is related to the heme-protein topology and the heme's exposure to solvent. In myoglobin, there is only one direct covalent bond between the heme and protein residues. The two charged isopropionate side chains extend into the solvent and interact strongly with solvent molecules, forming the dominant energy transfer pathway for heme cooling. The varying interactions between the heme and solvent in $\mathrm{Mb}$ in different solvents results in solvent dependent heme cooling rates. In cytochrome c, the heme is connected to protein residues by four hydrogen bonds to the isopropionate side chains and four covalent bonds, with no direct contact between the heme and solvent molecules. The heme cooling process is dominated by the direct interaction between the heme and protein residues, which is insensitive to the nature of the solvent. The distinct heme-solvent interaction character is dictated by the heme-protein environment designed to support the corresponding protein function.

Acknowledgment. We are grateful for the generous support of this research by the National Science Foundation (Grant No. CHE-0316551 and CHE-0750309) and Boston University's Center for Computational Science. We thank Prof. D. Tobias, University of California at Irvine, for providing the glycerol parameters.

\section{References and Notes}

(1) Spiro, T. G., Ed. Biological applications of Raman spectroscopy; Wiley-Interscience Publication: New York, 1988; Vol. 3. 
(2) Scott, R. A., Mauk, A. G., Ed. Cytochrome c. A multidisciplinary approach; University Science Books: New York, 1996. 162.

(3) Muenck, E.; Champion, P. M. Ann. N.Y. Acad. Sci. 1975, 244, 142-

(4) Henry, E. R.; Eaton, W. A.; Hochstrasser, R. M. Proc. Natl. Acad. Sci. U.S.A. 1986, 83, 8982-8986.

(5) Lian, T.; Locke, B.; Kholodenko, Y.; Hochstrasser, R. M. J. Phys. Chem. 1994, 98, 11648-11656.

(6) Miller, R. J. D. Annu. Rev. Phys. Chem. 1991, 42, 581-614.

(7) Genberg, L.; Heisel, F.; Mclendon, G.; Miller, R. J. D. J. Phys.

Chem. 1987, 91, 5521-5524.

(8) Henry, E. R.; Hochstrasser, R. M. Proc. Natl. Acad. Sci. U.S.A. 1987, 84, 6142-6146.

(9) Mizutani, Y.; Kitagawa, T. Science 1997, 278, 443-446.

(10) Mizutani, Y.; Kitagawa, T. Chem. Rec. 2001, 1, 258-275.

(11) Kitagawa, T.; Haruta, N.; Mizutani, Y. Biopolymers 2002, 61, 207213

(12) Straub, J. E.; Karplus, M. Chem. Phys. 1991, 158, 221-248.

(13) Li, H.; Elber, R.; Straub, J. E. J. Biol. Chem. 1993, 268, 17908 17916.

(14) Ma, J.; Huo, S.; Straub, J. E. J. Am. Chem. Soc. 1997, 119, 25412551.

(15) Sagnella, D. E.; Straub, J. E.; Thirumalai, D. J. Chem. Phys. 2000, 113, 7702-7711.

(16) Elber, R.; Karplus, M. Science 1987, 235, 318-321.

(17) Elber, R.; Karplus, M. J. Am. Chem. Soc. 1990, 112, 9161-9175.

(18) Sage, J. T.; Durbin, S. M; Sturhahn, W; Wharton, D. C.; Champion, P. M.; Hession, P.; Sutter, J.; Alp, E. E. Phys. Rev. Lett. 2001, $86,4966-4969$

(19) Okazaki, I.; Hara, Y.; Nagaoka, M. Chem. Phys. Lett. 2001, 337, $151-157$.

(20) Petrich, J. W.; Poyart, C.; Martin, J. L. Biochemistry 1988, 27, 4049-4060.

(21) Lim, M.; Jackson, T. A.; Anfinrud, P. A. J. Phys. Chem. 1996, $100,12043-12051$.

(22) Li, P.; Sage, J. T.; Champion, P. M. J. Chem. Phys. 1992, 97, 3214 3227

(23) Sagnella, D. E.; Straub, J. E. J. Phys. Chem. B 2001, 105, 70577063

(24) Bu, L.; Straub, J. E. J. Phys. Chem. B 2003, 107, 10634-10639.

(25) Ye, X.; Demidov, A.; Rosca, F.; Wang, W.; Kumar, A.; Ionascu, D.; Zhu, L.; Barrick, D.; Wharton, D.; Champion, P. M. J. Phys. Chem. A 2003, 107, 8156-8165

(26) Gao, Y.; Koyama, M.; El-Mashtoly, S. F.; Hayashi, T.; Harada,

K.; Mizutani, Y.; Kitagawa, T. Chem. Phys. Lett. 2006, 429, 239-243.

(27) Koyama, M.; Neya, S.; Mizutani, Y. Chem. Phys. Lett. 2006, 430, 404-408.

(28) Schomacker, K. T.; Champion, P. M. J. Chem. Phys. 1986, 84, 5314-5324.

(29) Spiro, T. G.; Li, X. In Biological applications of Raman spectroscopy; Spiro, T. G., Ed.; Wiley-Interscience Publication: New York, 1988 Vol. 3, Chapter 1, pp 1-37.

(30) Cartling, B. In Biological applications of Raman spectroscopy; Spiro, T. G., Ed.; Wiley-Interscience Publication: New York, 1988; Vol 3, Chapter 5, pp 217-248.

(31) Cianetti, S.; Negrerie, M.; Vis, M. H.; Martin, J.-L.; Kruglik, S. G. J. Am. Chem. Soc. 2004, 126, 13932-13933.

(32) Cremeens, M. E.; Fujisaki, H.; Zhang, Y.; Zimmermann, J.; Sagle, L. B.; Matsuda, S.; Dawson, P. E.; Straub, J. E.; Romesberg, F. E. J. Am Chem. Soc. 2006, 128, 6028-6029.

(33) Vos, M. H. Biochim. Biophys. Acta 2008, 1777, 15-31.

(34) Jongeward, K. A.; Magde, D.; Taube, D. J.; Traylor, T. G. J. Biol. Chem. 1988, 263, 6027-6030.

(35) Wang, W.; Ye, X.; Demidov, A. A.; Rosca, F.; Sjodin, T.; Cao, W.; Sheeran, M.; Champion, P. M. J. Phys. Chem. B 2000, 104, 1078910801.

(36) Negrerie, M.; Cianetti, S.; Vos, M. H.; Martin, J.-L.; Kruglik, S. G. J. Phys. Chem. B 2006, 110, 12766-12780.
(37) Bu, L.; Straub, J. E. J. Phys. Chem. B 2003, 107, 12339-12345. (38) Zhang, Y.; Fujisaki, H.; Straub, J. E. J. Phys. Chem. B 2007, 111, 3243-3250.

(39) Bushnell, G. W.; Louie, G. V.; Brayer, G. D. J. Mol. Biol. 1990, $214,585-595$.

(40) Brooks, B. R. Bruccoleri, R. E. Olafson, B. D.; States, D. J.; Swaminathan, S.; Karplus, M. J. Comput. Chem. 1983, 4, 187-217.

(41) MacKerell, A. D., J.; Bashford, D.; Bellott, M.; Dunbrack, R. L.; Evanseck, J. D.; Field, M. J.; Fischer, S.; Gao, J.; Guo, H.; Ha, S.; JosephMcCarthy, D.; Kuchnir, L.; Kuczera, K.; Lau, F. T. K.; Mattos, C.; Michnick, S.; Ngo, T.; Nguyen, D. T.; Prodhom, B.; Reiher, W. E., I.; Roux, B.; Schlenkrich, M.; Smith, J. C.; Stote, R.; Straub, J.; Watanabe, M.; Wiorkiewicz-Kuczera, J.; Yin, D.; Karplus, M. J. Phys. Chem. B 1998, $102,3586-3616$.

(42) Banci, L.; Gori-Savellin, G.; Turano, P. Eur. J. Biochem. 1997, 249, 716-723.

(43) Jorgensen, W. L.; Chandrasekhar, J.; Madura, J. D.; Impey, R. W.; Klein, M. L. J. Chem. Phys. 1983, 79, 926-935.

(44) Tobias, D. private communication.

(45) van Gunsteren, W. F.; Karplus, M. Biochemistry 1982, 21, 22592274.

(46) Verlet, L. Phys. Rev. 1967, 1, 98-103.

(47) Keyes, M. H.; Falley, M.; Lumry, R. J. Am. Chem. Soc. 1971, 93, 2035-2040.

(48) Taler, G.; Schejter, A.; Navon, G.; Vig, I.; Margoliash, E. Biochemistry 1995, 34, 14209-14212.

(49) Brayer, G. D.; Murphy, M. E. P. In Cytochrome c. A multidisciplinary approach; Scott, R A., Mauk, A. G., Eds.; University Science Books: New York, 1996; pp 103-166.

(50) Hildebrandt, P. In Cytochrome c. A multidisciplinary approach; Scott, R A., Mauk, A. G., Eds.; University Science Books: New York, 1996; pp 285-314.

(51) Wilson, M. T.; Greenwood, C. In Cytochrome c. A multidisciplinary approach; Scott, R A., Mauk, A. G., Eds.; University Science Books: New York, 1996; pp 611-634.

(52) Asher, S. A.; Murtaugh, J. J. Am. Chem. Soc. 1983, 105, 72447251.

(53) Meuwly, M.; Becker, O. M.; Stote, R.; Karplus, M. Biophys. Chem. 2002, 98, 183-207.

(54) Mizutani, Y.; Kitagawa, T. Bull. Chem. Soc. Jpn. 2002, 75, 623639.

(55) Ashihara, S.; Huse, N.; Espagne, A.; Nibbering, E. T. J.; Elsaesser, T. J. Phys. Chem. A 2007, 111, 743-746.

(56) Moritsugu, K.; Miyashita, O.; Kidera, A. J. Phys. Chem. B 2003, 107, 3309-3317.

(57) Goodno, G. D.; Astinov, V.; Miller, R. J. D. J. Phys. Chem. A 1999, 103, 10630-10643.

(58) Takayanagi, M.; Okumura, H.; Nagaoka, M. J. Phys. Chem. B 2007, $111,864-869$.

(59) Belogortseva, N.; Rubio, M.; Terrell, W.; Miksovska, J. J. Inorg. Biol. 2007, 101, 977-986.

(60) Northrup, S. H.; Boles, J. O.; Reynolds, J. L. Science 1988, 241, $67-70$.

(61) Pelletier, H; Kraut, J. Science 1992, 258, 1748-1755.

(62) Pappa, H. S.; Tajbaksh, S.; Saunders, A. J.; Pielak, G. J.; Poulos, T. L. Biochemistry 1996, 35, 4837-4845.

(63) Nocek, J. M.; Zhou, J. S.; Forest, S. D.; Priyadarshy, S.; Beratan, D. N.; Onuchic, J. N.; Hoffman, B. M. Chem. Rev. 1996, 96, 2459-2489. (64) Leesch, V. W.; Bujons, J.; Mauk, A. G.; Hoffman, B. M. Biochemistry 2000, 39, 10132-10139.

(65) Rosenfeld, R. J.; Hays, A.-M. A.; Musah, R. A.; Goodin, D. B. Protien Sci. 2002, 11, 1151-1159.

(66) Gray, H. B.; Winkler, J. R. Q. Rev. Biophys. 2003, 36, 341-372.

(67) Friesner, R. A.; Murphy, R. B.; Repasky, M. P.; Frye, Leah, L.; Greenwood, J. R.; Halgren, T. A.; Sanschagrin, P. C.; Mainz, D. T. J. Med. Chem. 2006, 49, 6177.

JP807499Y 